\title{
A Quantitative Study: Assessing the Knowledge Regarding the HPV Virus and Cervical Cancer Among Romanian Young Women Aged Between 18 and 24 years
}

\author{
Monica Brinzac ${ }^{1}$, Ioana $\mathrm{Coci}^{2}$, Valeria Ionascu ${ }^{3}$
}

\begin{abstract}
Human Papillomavirus (HPV) it is the most common cause of cervical cancer globally and Romania has the highest prevalence rate of cervical cancer in Europe. (Ene, L. (2015)).

An approximation of 4443 cases of cervical cancer are diagnosticated annually in Romania. This disease is the third most prevalent cancer among women and second most prevalent between women aged 15- 44 years old. (Ferlay, J., Soerjomataram, I., \& Ervik, M. (2013)).

This study examines Romanian women between 18 and 24 years regarding their knowledge and attitudes on HPV, cervical cancer and HPV vaccine. The study sample consists of 200 women who answered the online questionnaire disseminated on Facebook through Facebook ads.

Most respondents stated that their knowledge was average or above average. However, the answers did not reflect that the knowledge was average towards high as many did not know the symptomatology of the disease nor how the disease develops or possible outcomes. As well, the knowledge regarding the connection between HPV and cervical cancer, Pap smear is significantly low.

It is essential to increase the knowledge of women regarding this topic as sexual transmitted diseases are a major problem in Romania.
\end{abstract}

Keywords: Public Health, STDs, HPV, Cervical cancer

\section{Introduction}

Human papillomavirus is one of the most common causes of sexually transmitted infections. More than 60 types of HPV have been identified; about one-third of which can be spread through sexual contact.(Pitts \& Clarke, 2002)

According to American Cancer Society, HPV causes the production of two known proteins that triggers tumor suppressor genes. This allow the cervical lining cells to grow too much and to develop changes in additional genes, which can lead to cervical cancer. (American Cancer Society, 2017)

In România, sexual behaviour poses a real threat among youngsters. The lack of sexual education creates a two fold incidence of cervical cancer compared to countries as Finland, Luxembourg and France, where sexual education and sexual transmitted

${ }^{1}$ Student in Public Health at the Cluj School of Public Health of Babeș-Bolyai University in Cluj-Napoca, Romania.

2Student in Public Health at the Cluj School of Public Health of Babeş-Bolyai University in Cluj-Napoca, Romania.

${ }^{3}$ Student in Public Health at the Cluj School of Public Health of Babeș-Bolyai University in Cluj-Napoca, Romania. 
diseases prevention programmes are common. "Evaluation of women knowledge and attitude regarding cervical cancer early detection" (Bădulescu, 2011)

This topic is of increased interest as Romania has the highest rate of cervical cancer in Europe. (Ene, 2015). Despite the fact that in Romania in 2008 a vaccination campaign against HPV, only $2,5 \%$ of the targeted population had the vaccine. (Catrinel \& Adriana, 2012) A study that assesses the knowledge and attitudes regarding this topic is necessary for making this campaign more efficient.

\section{Methods}

\subsection{Study settings}

The setting of the study was online, at national level. The target group of the research was selected through parameters established on Facebook, based on their previous searches. For this parameters, Facebook uses the previous searches and internet history of one person to match it with an specific ad, or in this case, questionnaire. A few of the parameters used for selecting the study population are: cancer, cervix, cervical cancer, HPV, condom, virus, STD, sexually transmitted diseases.

\subsection{Target population}

The target population of this study is represented by all women aged 18 to 24 years old from Romania.

\subsection{Study population}

The study population is represented by all women aged 18 to 24 years old that met the pre-set parameters on Facebook. Our study population consists of 200 women. This age group was chosen because the period from 15 to 24 years old is named "Young adults" and according to studies, this age group is more predisposed to sexually transmitted diseases. As well, the prevalence of Human papilloma virus is higher in this age group. (Center for Disease, Control and Prevention, 2015).

This target group is relevant for this research because the HPV vaccine is still available for them. (Despre vaccin, 2016)

The chosen population was over 18 because, in this case, it would not require parent consent for completing the questionnaire.

\subsection{Study design}

The study was quantitative as the data was obtained from dissemination of an online questionnaire. The goal of this was to assess the general knowledge level regarding HPV and cervical cancer of the target group.

\subsection{Data and measurements}

In this study it was measured different concepts that influence the knowledge level regarding the Human papillomavirus and cervical cancer among women aged 18 to 24 It was measured: years

old. 
Socio- demographic characteristics: gender, age, marital status, residence, ethnicity, education level, monthly income;

- $\quad$ Sexual history: virginity, contraceptive methods use, number of partners;

- $\quad$ Knowledge regarding HPV and HPV vaccine;

- Knowledge on Cervical cancer;

- $\quad$ Acknowledgement of risk of contracting the diseases;

The data was gathered through a 32-item questionnaire segregated in 5 categories developed to measure the knowledge and understanding of HPV and cervical cancer, to assess awareness and knowledge of HPV vaccination, and to assess the knowledge on pap-smear tests. The questionnaire was divided as it follows:

- $\quad$ A demographic section to collect basic information on the respondent

- A section on Human Papillomavirus that assessed their knowledge on this topic

- A cervical cancer section through which we gathered their previous knowledge

- $\quad$ A section that assessed their knowledge on screening methods

- A vaccination section that evaluated their attitudes

The questionnaire was pilot tested on a sample of 40 women. After their responses and their feedback we adjusted the questionnaire in order to have the maximum coverage and the language used is accessible to everyone.

\subsection{Data collection}

During this research, the collection of data was made online, through a questionnaire disseminated on Facebook, made with Google Forms. The data were collected beginning with the 4th of April and ending on the 25th of May 2018.

The mandatory step before completing the questionnaire was the informed consent which was the welcome screen of the online questionnaire. In the said consent it was presented briefly the project, the aim of it, the voluntary participation in the study, what a participant should do, data protection and contact person.

\subsection{GDPR compliance}

The data collected was anonymous as none of the questions did not require any personal data and the data obtained is kept in a safe environment, secured by a password.

\subsection{Data analysis}

The analysis of the data was made with Statistical Package for the Social Sciences (SPSS) and Google forms, as the study had of interest only descriptive statistics.

\section{Results}

\subsection{The study sample}

Of the 200 women who participated, the mean age was 20.99 years (range 1824). Fifty-seven point seven percent $(n=113)$ were in a relationship, $33.9 \%(n=68)$ single and $8.5 \%(n=19)$ married. Most women were living in a city $(84.1 \% n=165)$ of Romanian ethnicity $(95.8 \%, n=189)$ and $65.1 \%(n=124)$ of the sample had a high school degree, $21.7 \%(n=43)$ had finished universitary studies. Forty one point eight $(n=82)$ reported the monthly income between 900 and 1900 RON (200 and 400 EUR) while 
$36.6 \%(\mathrm{n}=70)$ declared that their monthly income is below 900 RON. $163(83.1 \%)$ of our respondents started their sexual life with the mean age of 17.79 (range 14-24). Only $37.6 \%(n=73)$ stated that they always use contraceptive methods during sex while $42.9 \%$ $(n=88)$ declared that they use sometimes, rarely or never. From our sample, $142(73 \%)$ of respondents have between 0 and three sexual partners

\subsection{HPV}

Table I summarizes the responses to questions about Human Papillomavirus. Respondents' declared understanding of HPV was good overall- 81.5\% ( $\mathrm{n}=158)$ heard of HPV before, $69.8(n=138)$ assessed their knowledge average and above average The majority $(65.1 \%$; $\mathrm{n}$ 127) was aware that the virus can affect both men and women and $94.7 \% \quad(n=182)$ chose that the transmission of HPV is sexually. Respondents demonstrated good understanding of the risks of contracting the disease, $75.7 \%(n=143)$ knowing that multiple sexual partners increases the chance of contracting the disease while the symptomatology of the STD created uncertainty 38.1\% $(n=75)$ declared that $\mathrm{HPV}$ is sometime symptomatic while $37.7 \% \quad(n=74)$ declared that it is without symptoms.

\section{$\underline{\text { Table } 1}$}

$\begin{array}{llll}\text { Have you ever heard of HPV? } & \mathrm{N} & \% & \text { Table } 1 \text { summarizes the } \\ \text { Yes } & 158 & 81.5 & \text { answers of the second section. } \\ \text { No } & 23 & 10.1 & \\ \text { I don't know/ I'm not sure } & 19 & 8.5 & \end{array}$

How would you assess your knowledge level?

$\begin{array}{lll}0 & 21 & 9.5 \\ 1 & 41 & 20.6 \\ 2 & 73 & 37.6 \\ 3 & 51 & 25.9 \\ 4 & 14 & 6.3\end{array}$

Can HPV affect both men and women?

Yes

Only men $\quad 0$

Only women 35

I don't know/ I'm not sure $\quad 38$

65.1

0

16.9

18

How can you contract HPV?

$\begin{array}{lll}\text { Sexually } & 182 & 94.7 \\ \text { Through saliva } & 26 & 12.2 \\ \text { Through air } & 0 & 0 \\ \text { Another mean } & 20 & 9 \\ \text { I don't know/ I'm not sure } & 18 & 8.5\end{array}$

With of the following increases the risk of contracting HPV?

Multiple sexual partners $\quad 143 \quad 75.7$

Multiple sexual partners of $\quad 89 \quad 47.1$

your sexual partner

Early sexual activity $\quad 26 \quad 13.8$

Lack of condom use $\quad 135 \quad 71.4$

Smoking $\quad 3 \quad 1.6$

I don't know/ I'm not sure $\quad 18 \quad 9.5$

You think that HPV is..

Sometime symptomatic

Without symptoms

I don't know/ I'm not sure

$\begin{array}{ll}28 & 13.2 \\ 75 & 38.1 \\ 74 & 37.6 \\ 23 & 11.1\end{array}$




\subsection{Cervical cancer}

The respondents have a good knowledge on cervical cancer as $97.9 \%(n=190)$ of the sample have heard before of the cancer, while only $69.8 \%(n=135)$ knew that there is a connection between cervical cancer and HPV. Of those who declared a connection, $77.8(\mathrm{n}=105)$ stated that PV can cause the cancer.

\subsection{Testing}

\begin{tabular}{|c|c|c|c|}
\hline & $\mathrm{N}$ & $\%$ & Table 2 \\
\hline \multicolumn{4}{|c|}{ Have you ever heard of Pap-smear? } \\
\hline No & 10 & 5 & \\
\hline Yes & 189 & 94.5 & 1 able 2 \\
\hline I don't know/ I am not sure & 1 & 0.5 & $\begin{array}{l}\text { summarizes the } \\
\text { answers from the }\end{array}$ \\
\hline \multicolumn{3}{|l|}{ What is the Pap-smear? } & fifth section. \\
\hline Vaginal exam & 111 & 58.7 & \\
\hline Treatment against cancer & 4 & 2.1 & \\
\hline Test for STDs & 65 & 34.4 & \\
\hline I don't know/I am not sure & 9 & 4.8 & \\
\hline \multicolumn{4}{|l|}{ Where can you do a Pap-Smear? } \\
\hline Home & 0 & 0 & \\
\hline At your GP's office & 3 & 1.6 & \\
\hline At a qualified doctor & 183 & 96.8 & \\
\hline I don't know/ I am not sure & 3 & 1.6 & \\
\hline
\end{tabular}

What is the recommended frequency of the test?

$\begin{array}{lll}\text { Annually } & 138 & 73 \\ \text { Once every } 3-5 \text { years } & 29 & 15.3 \\ \text { Once in 10 years } & 1 & 0.5 \\ \text { Only once } & 0 & 0 \\ \text { It does not matter } & 0 & 0 \\ \text { I don't know/ I am not sure } & 21 & 11.1\end{array}$

$\begin{array}{lcc}\text { What do you think that abnormal results of a } & \text { Pap-smear could mean? } \\ \text { Pre-cancerous cells } & 128 & 67.7 \\ \text { Cancer } & 11 & 5.8 \\ \text { Vaginal infection } & 28 & 14.8 \\ \text { It does not matter } & 0 & 0 \\ \text { I don't know/ I am not sure } & 22 & 11.6\end{array}$

The understanding of HPV testing was reported to be high as $94.5 \%(n=189)$ of the sample declare to have heard of the Pap- smear test. From those who have heard, only $58.7 \%(n=111)$ stated that it is a vaginal exam, while the majority, $96.8 \%(n=183) \mathrm{knew}$ that it is a test that should be performed only by a qualified doctor. One hundred thirty eight $(73 \%)$ of our sample assessed correctly the recommended frequency of the test, while only $67.7 \%(n=128)$ chose that abnormal test result can indicate pre-cancerous cells. 


\subsection{Vaccination}

This section has shown a gap in the knowledge of the sample as only $69 \%$ $(n=138)$ had acknowledged the existence of the vaccine while $31 \%$ declared that they do not know or they are not sure. The target group of the vaccine had been proven to be a question that put our sample at difficulty as $52,4(\mathrm{n}=104)$ declared that the vaccine is only for women, 33,8 ( $\mathrm{n}=68)$ stated that the vaccine is for both genders while $29 \%$ $(\mathrm{n}=13.8)$ said that they do not know or they are not sure.

\section{Discussions}

The reported knowledge of our sample has shown to be good as for all the questions more than half of the sample had adequate understanding of the Human papillomavirus and cervical cancer, of the existence of screening methods or available vaccines.

In contrast, the overall tendency of the sample was for most of them to be aware of the existence of the mentioned diseases, of testing process and vaccine existence, but then to lose their expertise when having to give details on the concepts reminded. This trend was noticed in all section as the first questions assessed their awareness of the HPV, cervical cancer, Pap- smear and vaccination, while the following needed a more comprehensive knowledge (i.e. $94.5 \%$ of the sample heard of Pap-smear while only $58.7 \%$ what it is). This reveals that Romanian women aged between 18 and 24 years have a grasp on the concepts presented, but no real knowledge. This represents an issue as Romania has no sexual education programme and the prevalence of sexual diseases is high.

This study highlights the need for more education campaigns as most respondents heard about the conditions mentioned, but did not hold a comprehensive understanding of the condition or of the available screening or vaccine.

This is of great importance when designing a vaccination campaign or a intervention programme because it is an aspect that needs to be taken into consideration. The results of the present study would be of great benefit in improving the previous vaccination campaign as it was not effective, vaccination being made in only $2,5 \%$ of the target group. Knowing the areas that need to be tackled can make the designing of tailored campaigns much easier.

This result of the research support the need of introducing a sexual education course in the national curricula. As Romania has two fold incidence compared to countries as Finland, Luxembourg și France, where sexual education programmes are commonly met. (Bădulescu, 2011) Health literacy is other area that can benefit from introduction of a course as many of the women in the sample group did no show real understanding of the conditions or did not know what the screening results indicate nor the options they have.

These findings are appalling as our sample is educated, with $97,4 \%(n=192)$ has a high school degree or higher, with an age between 18 and 24 years, with increased access to information and living in an era where internet access is regarded as a basic need. 


\section{References}

Ene, L. (2015). Cervical HPV infection in Romanian women infected with HIV during early childhood. International Journal of STD \& AIDS, 1079-1085.

Ferlay, J., Soerjomataram, I., \& Ervik, M. (2013). Cancer Incidence and Mortality Worldwide . IARC Cancer Base No. 11

Pitts, M., \& Clarke, T. (2002, December 1). Human papillomavirus infections and risks of cervical cancer: what do women know? Retrieved October 18, 2017, from Oxford Academic: https://academic.oup.com/her/article/17/6/706/697257/Human-papillomavirus-infections-andrisks-of

American Cancer Society (2016, November) Do We Know What Causes Cervical Cancer? Retrieved October 17, 2017, from CAUSES, RISK FACTORS, AND PREVENTION: https://www.cancer.org/cancer/cervical-cancer/causes-risks-prevention/what-causes.html

Bădulescu, F. (2011). Evaluation of women knowledge and attitude regarding cervical cancer early detection. Retrieved October 17, 2017, from US National Library of Medicine: https://www.ncbi.nlm.nih.gov/pubmed/21424031

Catrinel, C., \& Adriana, B. (2012). "Who will take the blame?": Understanding the reasons why Romanian mothers decline HPV vaccination for their daughters. Vaccine, 6789-6793.

Center for Disease, Control and Prevention. (2015). STDs in Adolescents and Young Adults. Retrieved October 18, 2017, from Center for Disease, Control and Prevention: https://www.cdc.gov/std/stats14/adol.htm

Despre vaccin. (2016). Despre vacin. Retrieved October 18, 2017, from VACCINUL HPV: http://desprevaccin.ro/vaccinul-hpv/ 